\title{
NHS recruitment crisis
}

Tom King

BDA Policy Adviser

The BDJ Upfront section includes editorials, letters, news, book reviews and interviews. Please direct your correspondence to the News Editor,

Kate Quinlan at k.quinlan@nature.com. Press releases or articles may be edited, and should include a colour photograph if possible.

$\mathrm{I}$ $t$ is no understatement to say that the face and shape of the dental profession is changing rapidly. This year - among NHS GDPs in England - women were, for the first time, a majority. This reflects a long-term trend in the profession and this majority is now here to stay. ${ }^{1}$ The other stark long-term trend is the decline in the number of practice owners. Back in 2006, roughly $40 \%$ of GDPs were practice owners, with the remainder being associates. Today, approximately $85 \%$ are associates and $15 \%$ are practice owners, and in the NHS in England there are only around 2,500 practice owners left. $^{2}$

Yet despite the increasing proportion of associates in the workforce, this does not mean that practices are finding it easier to recruit one. The last few years have seen growing issues with associate recruitment that have spread from localised problems to a national crisis.

This is something we keep track of at the BDA and we use the evidence we gather to make the case for improvements in dentists' pay, investment in dentistry and contract reform in England and Wales. This year, we've also worked with BDJ Jobs to produce a comprehensive report on the state of the UK dental recruitment market to help guide both associates and practice owners as they make career and business decisions.

Research undertaken by the BDA shows clearly the pressures practices are under. In $2017-18,70 \%$ of practice owners who had tried to recruit an associate reported difficulties doing so. The problems are even worse for practice owners with high-levels of NHS commitment trying to recruit; with $82 \%$ experiencing issues.

While a national problem, data from BDJ Jobs show that regional variations remain. As might be expected, application rates for associate positions in London and the South East of England are well above the national average, with Northern Ireland, Scotland and Wales all struggling for responses by comparison. Looking more locally, the hard-to-recruit areas we all hear about like Cornwall and Cumbria both fall below the national average on advert responses and Lincolnshire in particular fares really badly. But what is driving these difficulties? Looking at the GDC's figures shows this is not a straightforward story of a lack of dentists. There were nearly 42,000 dentists registered according to the latest annual report and this number has increased slightly over the last few years. ${ }^{3}$ The number of NHS primary care dentists across the UK too has been on the rise and now stands at just over $30,000{ }^{4}$

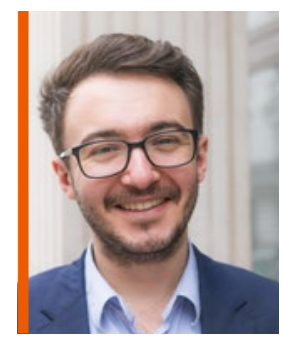

\section{'The last few years have seen growing issues with associate recruitment that have spread from localised problems to a national crisis'} dentists to their practice. There are also issues filling temporary positions to cover long-term absences like maternity or sickness leave, but still by far the biggest issue was simply not receiving enough, or any, applicants.

The consequences of failing to recruit can be dire. In the last financial year, NHS practices in England had a total of $£ 138$ million clawed back for under-delivering on UDA targets. ${ }^{5}$ High levels of clawback are also seen in Wales and, although different systems, practices in Northern Ireland and Scotland are also feeling the strain. While this will not solely be down to recruitment problems, they
However, these headcount figures only give us part of the picture, as while on the register or a performers' list, this doesn't mean that all of these dentists are working full-time. Many will be, but others will be working part-time, combining wet-fingered dentistry with nonclinical roles or maintaining their registration while on maternity leave or a career break. Unfortunately, there just aren't clear statistics on exactly how much of this is going on and so we don't have a clear sense of the so-called 'full-time equivalent' number of dentists. The true workforce capacity remains a mystery.

The recruitment issue, then, seems to be not that there are not enough dentists in the UK, but that too few are willing to work on the NHS and, where they are, they don't want to do so full-time. This is backed up by our research where practice owners told us that associates are reluctant to work on the NHS or certainly don't help when practices are already facing a whole range of challenges from a sustained lack of government investment and ever higher NHS charges to increasing scrutiny on claims from the BSA.

All this serves to underscore the need for urgent progress in making the NHS a more attractive working environment. It has long been clear that the current system just isn't fit for purpose and these long-term issues are now finally coming to a head.

\section{References}

1. NHS. NHS Dental Statistics for England 2018-19, Annual Report. 2019.

2. NHS England's Information and Evidence on GMPs and GDPs for the 2019 DDRB.

3. GDC. Annual Report, 2019.

4. NHS Digital, ISD Scotland. Northern Ireland Statistics and Research Agency and StatsWales (Figures for England include TDS dentists).

5. NHS BSA, NHS payments to dentists - Data for 2018 to 2019, 2019. 